\title{
Impact of light-rail implementation on labor market accessibility: A transportation equity perspective
}

Yingling Fan ${ }^{a}$

University of Minnesota
Andrew Guthrie

University of Minnesota

\author{
David Levinson
}

University of Minnesota

\begin{abstract}
This study seeks to examine transit's role in promoting social equity by assessing the before-after impacts of recent transit changes in the Twin Cities, including the opening of the Hiawatha light-rail line, on job accessibility among workers of different wage categories. Geospatial, descriptive, and regression analyses find that proximity to light-rail stations and bus stops offering direct rail connections are associated with large, statistically significant gains in accessibility to low-wage jobs. These gains stand out from changes in accessibility for the transit system as a whole. Implications of the study results for informing more equitable transit polices are discussed.
\end{abstract}

\section{$1 \quad$ Introduction}

Public transit is more than a means of transportation. It serves as a key component in addressing poverty, unemployment, and equal opportunity goals (Blumenberg and Manville 2004; Rast 2004; Sen et al. 1999). In the United States, low-income households have relatively lower auto ownership rates compared to other households. According to the National Household Transportation Survey, 7.7 percent of all households have no private vehicles, compared to 17 percent of "low-income households" and 30 percent of "poor households" ${ }^{1}$ with no private vehicles (Guiliano 2005). Further, while low-income households disproportionally live in central cities (Glaeser, Kahn, and Rappaport 2008), their suitable job opportunities (i.e., low-paying jobs) are common in suburban areas with limited affordable housing and poor transit service (Kain 1968, 1992). Even worse, many of these jobs require working nights or weekends when public transit service is often reduced or nonexistent (Guiliano 2005; Rast 2004; Sanchez, Shen, and Peng 2004).

Such well-documented evidence on "uneven access to job opportunities" led to a series of planning and policy efforts to address the transportation problems of low-income residents and welfare recipients (Blumenberg, Ong, and Mondschein 2002). At the federal level, the Transportation Equity Act for the 21st Century (TEA-21) established the Job Access and Re-

1 Guiliano used the Department of Housing and Urban Development's (HUD) definition of low income to define "low-income" households. The HUD definition corresponds to roughly 85 percent of a region's median household income. Guiliano used the federal poverty threshold to define "poor" households. The federal poverty threshold is much more restrictive than HUD's low-income threshold.

a yingling@umn.edu verse Commute (JARC) program in 1998 and authorized an annual amount of $\$ 150$ million for JARC grants for fiscal years 1999 through 2005 (Sanchez and Schweitzer 2008). In 2005, another landmark bill, the Safe, Affordable, Flexible, Efficient Transportation Equity Act: A Legacy for Users (SAFETEA$\mathrm{LU})$, authorized a total of $\$ 727$ million for JARC grants for fiscal years 2006 through 2009 (Sanchez and Schweitzer 2008).

Despite high expectations that transit improvements would positively affect employment status for low-income persons, employment benefits associated with transit improvements are often predicted but not empirically demonstrated (Rosenbloom 1992; Rosenbloom and Fielding 1998). Out of the few studies that rigorously examined the impact of transit improvements on employment, only studies in Los Angeles, California, found positive effects of transit accessibility on employment outcomes (Kawabata 2002, 2003; Ong and Houston 2002). Studies in other regions show little or no association between transit availability/quality and employment participation (Bania, Leete, and Coulton 2008; Cervero, Sandoval, and Landis 2002; Sanchez 1999; Sanchez et al. 2004; Thakuriah and Metaxatos 2000). It is also worth noting that studies in Los Angeles focused on carless welfare recipients in particular, while other studies focused on general welfare clients (Cervero et al. 2002; Sanchez et al. 2004), female welfare recipients (Thakuriah and Metaxatos 2000), welfare leavers (Bania et al. 2008), or all adults (Yi 2006).

When explaining the inconsistent evidence in the literature, some researchers cite difficulties in determining the effectiveness of transit programs for disadvantaged groups, including the lack of accepted performance measures and the inability to control for intervening factors affecting employ-

Copyright 2012 Yingling Fan, Andrew Guthrie, and David Levinson.

Licensed under the Creative Commons Attribution - NonCommercial License 3.0. 
ability (Sanchez 2008). Further, as low-wage workers benefit from increased job access, many purchase automobiles, ending their transit dependency and increasing the difficulty of assessing transit's employment outcome impacts (Sanchez et al. 2004). Many researchers also concede that inconsistencies in the literature partially reflect the ineffectiveness of US transit in meeting the needs of disadvantaged groups (Blumenberg and Manville 2004).

The review above seems to be sending a mixed message: While transit is important to low-income people, transit improvement may not help them. This message underscores the importance of evaluating major transit investments from a transportation equity perspective. Major transit capital projects - particularly rail transit lines - represent large, one-time expenditures, with total construction costs generally in the hundreds of millions of dollars. In the past, critics of transit improvements have often pointed out instances in which ridership gains were greatly overstated during planning while capital and operating costs were greatly understated. Examples include the frequently-touted criticism of Buffalo's populationlosing light-rail line as well as projects from Baltimore, Miami, Pittsburgh, Sacramento, and Portland (Pickrell 1992). In addition, rail transit investments have been characterized as serving mainly middle-class suburbanites, sometimes to the detriment of poorer, transit-dependent urbanites: the landmark civil rights suit brought by the Bus Riders Union in Los Angeles provides a prime example (Niece 2003). Given these circumstances, knowing the scope and size of job accessibility benefits associated with specific types of transit investments (e.g., light rail) for low-income residents will help policymakers make more informed investment decisions toward an equitable transportation system.

This study aligns with the research needs for quantifying the job accessibility impacts of transit improvements among low-income individuals. We focus on a recent light-rail implementation in the Twin Cities - the Hiawatha light-rail line-and examine how such an implementation has shaped job accessibility in the region. More specifically, we attempt to answer the following two questions: Does the light-rail implementation make job opportunities more accessible to lowwage workers, contributing to improvements in transportation equity? How do the benefits for low-wage workers compare to those of medium- and high-wage workers?

The next section describes the study area and population. This is followed by a map analysis and a mean comparison analysis of transit-based job accessibility before and after lightrail transit (LRT) implementation. A regression analysis follows, estimating changes in transit-based job accessibility at the census block level as a function of proximity to LRT stations and other transit stops, as well as socioeconomic characteristics of blocks. The paper concludes with policy implications of the study findings.

\section{Study area and population}

This paper centers on the Hiawatha light-rail line, which connects downtown Minneapolis with several South Minneapolis residential neighborhoods, the Minneapolis-Saint Paul International Airport, and the Mall of America area in suburban Bloomington. Since its opening in December 2004, the line has attracted about 30,000 average weekday boardings, making it the most heavily used transit route in the Twin Cities metro area (American Public Transportation Association 2009). Figure 1 shows the location of the light-rail line relative to regional landmarks, as well as to the bus routes in Metro Transit's ${ }^{2} \mathrm{Hi}$ Frequency network (shown as bold yellow lines), which offers quarter-hourly (minimum) rail/bus service from 6:00 a.m. to 7:00 p.m. weekdays and 9:00 a.m. to 6:00 p.m. Saturdays, and the rest of the transit system.

Given this research's transportation equity perspective and its focus on job accessibility, an important study population is low-wage workers (also can be referred to as "the working poor") who maintain regular employment but remain in relative poverty. However, quantitatively defining this population has proven to be a difficult task (DeFina 2007). Some define the working poor as families with a working head of household who earns less than the federal poverty threshold for his or her household's size/composition (Gardner and Herz 1992; Klein and Rones 1989). Others, however, point out that the official poverty line does not consider taxes, in-kind transfer payments such as food stamps, working expenses including child care and transportation, disparities with average standards of living, or income inequalities among the poor (Joassart-Marcelli 2005; Wertheimer 1999). The national Working Poor Families Project (WPFP) simply defines working poor as low-income individuals and families that struggle to meet basic needs (Waldron, Roberts, and Reamer 2004). The WPFP uses incomes of less than 200 percent of the federal poverty threshold as a benchmark for low income. In 2006, the poverty threshold for a family of three with one child under 18 was $\$ 16,227$ (United States Census Bureau 2006), meaning that families earning less than $\$ 32,454$ would be considered low income. Based on this WPFP definition, there were approximately 9.6 million low-income working families in the United States in 2006, of

2 Metro Transit is the lead transit agency in the Twin Cities region, providing roughly 90 percent of the 78 million transit trips taken annually in the Twin Cities. Metro Transit operates under the Metropolitan Council-the regional planning agency serving the Twin Cities seven-county metropolitan region. 
which 2.5 million were considered to be in poverty based on official federal government definitions.

Existing definitions mentioned above (despite being inconsistent) have assisted various nonprofit organizations and public agencies in identifying the working poor population and their specific needs. However, key challenges remain when it comes to practical applications of these definitions. The United States Census Bureau provides a limited amount of information on income and earning — such as median household income at the census block group level and the percentage of families/children under the federal poverty line within the census block group - that cannot be easily translated into information on the number of working poor in the area.

In this research, we employ the Census Bureau's Longitudinal Employer and Housing Dynamics (LEHD) dataset. The nature of the dataset poses limitations on how we define our study population. This annually collected dataset counts individual wages in each of three categories (less than $\$ 1200$ per month, $\$ 1200-\$ 3400$ per month and more than $\$ 3400$ per month) at the census block level (United States Census Bureau, 2009). For the purposes of this research, jobs in the lowest category-equivalent to less than $\$ 14,400$ per year and accounting for roughly 25 percent of the jobs in the Twin Cities' transit service area-are considered low-wage jobs and used as indicators of the entry-level jobs the working poor are more likely to be qualified for. Jobs in the middle category (\$1200-\$3400 per month) are considered medium-wage jobs. Jobs in the highest wage category, considered high-wage jobs, are equivalent to more than $\$ 40,800$ per year and account for 42 percent of transit-served jobs. For context, 2006 per-capita income in the seven Twin Cities metro counties was $\$ 31,400$ (United States Census Bureau 2007).

Figure 2 locates low-wage jobs and low-wage workers (as defined above) in 2002 before the implementation of the Hiawatha LRT. These maps make it clear that spatial mismatch between jobs and housing exists among low-wage workers

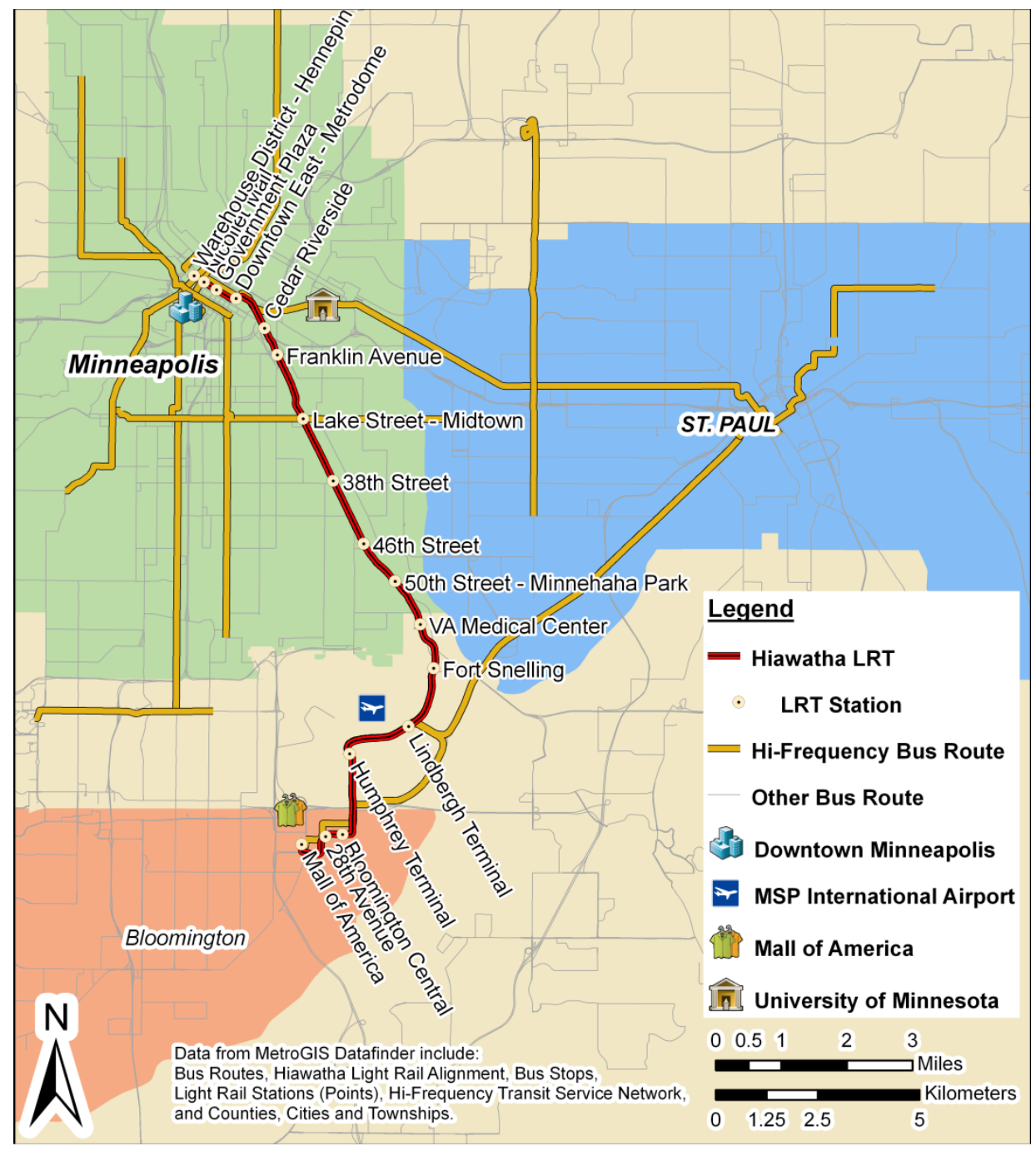

Figure 1: Twin Cities transit system in 2009. 


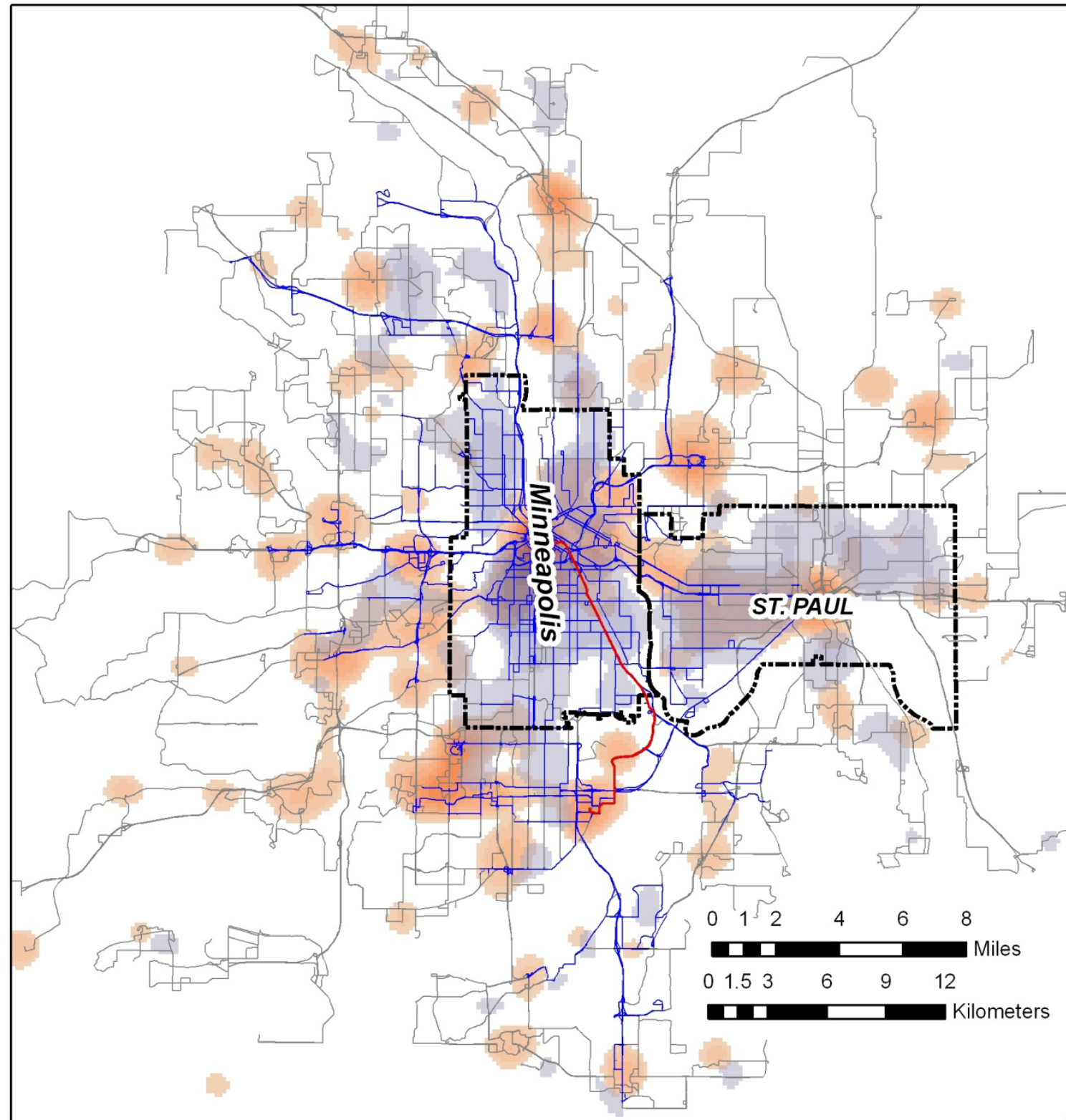

Legend

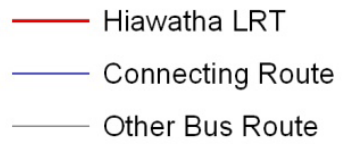

Residence of low-wage workers (Workers per acre)

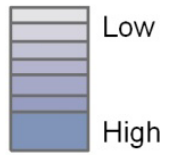

Worksites of low-wage workers (Jobs per acre)

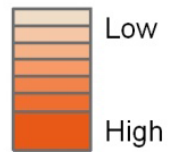

Figure 2: Locations of low-wage workers/jobs in 2002 relative to LRT and bus connections.

Note: Connecting routes are defined as parts of routes serving light-rail stations scheduled so that a rider can travel by bus to a light-rail stop, wait five minutes (i.e., half the average LRT headway) for a train, and travel at least one stop by LRT within 30 minutes. 
in the Twin Cities region. High residential concentrations of low-wage workers are mainly located in the two central cities-Minneapolis and St. Paul—yet low-wage job clusters are dispersed across urban and suburban areas in the region. This pattern puts special emphasis on effective transit as means of promoting social equity in the region.

In addition to showing the Hiawatha LRT line, Figure 2 illustrates bus routes with direct LRT connections. As shown in Figure 2, these bus-LRT connection routes help to connect residential areas of low-wage workers to low-wage job clusters. As such, we expect that the Hiawatha LRT implementation, along with these bus-LRT connection routes, has had positive impacts on job accessibility for low-wage workers.

\section{Accessibility analysis}

This research applies a cumulative opportunity approach to calculate transit-based job accessibility at the census block level. Only blocks served by transit (defined by a quarter-mile [ $400 \mathrm{~m}]$ maximum distance from any transit stop) are considered. Job accessibility is calculated for each wage category, including low-, medium-, and high-wage categories. As such, our accessibility calculation counts how many low-, medium-, and high-wage jobs can be reached from each block centroid within a predetermined travel time. We use 30 minutes as the travel time threshold. The 30-minute travel time includes bus/rail riding time, walking time ${ }^{3}$ (from the origin block centroid to the starting transit stop and from the ending transit stop to the destination block centroid), and waiting time, which is dependent on frequency/headway of the specific bus route at specific time of the day. We allow a maximum of one transfer during the 30-minute travel time. (Multiple transfers are not allowed due to limited geocomputing capacity. $)^{4}$ For transit travel with one transfer, the 30-minute travel time will include additional transfer-related walking time and transfer-related waiting time.

As transit service levels change throughout the day, accessibility measures $(A)$ were produced for each hour from 5:00 a.m. to 9:00 p.m. on weekdays using the cumulative opportunity calculation method described above, creating a total of 16 one-hour, metro-wide snapshots of job accessibility by transit. These 16 time-specific accessibility measures $\left(A_{5 a m}, A_{6 a m}, \ldots\right.$, $\left.A_{9 p m}\right)$ are then converted into a weighted average accessibility

3 Walking time is computed using an average walking speed of 3.4 miles per hour (1.52 meters per second).

4 This limitation leads to our selection of 30 minutes as the travel time threshold. Given our one-transfer assumption and that longer transit trips often mean multiple transfers, larger travel time thresholds are likely to skew the accessibility calculation results. index using the equation:

Weighted Average Accessibility Index $=\bar{A}_{\text {peak }} * P_{\text {peak }}+$ $\bar{A}_{\text {nonpeak }} * P_{\text {nonpeak }}$

$\bar{A}_{\text {peak }}$ is the average accessibility of all peak hours ${ }^{5} ; \bar{A}_{\text {nonpeak }}$ is the average accessibility of all off-peak hours; $P_{\text {peak }}$ is the percentage of transit trips made within all peak hours; $P_{\text {nonpeak }}$ is the percentage of transit trips made within all off-peak hours. $P_{\text {peak }}$ and $P_{\text {nonpeak }}$ are calculated using a 2006 on-board survey of transit riders conducted by Metro Transit (SRF Consulting Group 2006). Separate averages were produced for low-, medium-, and high-wage jobs based on the travel behavior of riders in that wage group- 54.88 percent peak and 45.12 percent off-peak for low-wage riders; 63.93 percent peak and 36.07 percent off-peak for middle-wage riders; 80.05 percent peak and 19.95 percent off-peak for high-wage riders.

Since the Hiawatha LRT line was fully implemented in December 2004, changes in job accessibility by transit after the Hiawatha implementation are calculated using 2002 and 2006 employment/transit network data. In this research, changes in low-wage job accessibility are the main focus. The mediumand high-wage job categories are included for comparison.

\subsection{Map analysis}

Figure 3 shows pre- and post-LRT accessibility to low-wage jobs via transit, along with changes in accessibility between observations. It is immediately apparent that major low-wage employment accessibility gains occurred along the Hiawatha LRT corridor, as well as along bus routes offering LRT connections - broadening accessibility gains well beyond the LRT corridor. Areas not adjacent to the LRT stations or bus stops with bus-LRT connections mostly show modest gains, no change, or a slight decline $e^{6}$ in accessibility to low-wage jobs.

\subsection{Descriptive statistics}

To provide a statistical quantification of the before-after changes in accessibility, we performed descriptive analyses of beforeafter changes in weighted average accessibility in three wage categories (low, medium, and high). The dependent variables

5 Based on the times Twin Cities transit providers charge peak and offpeak fares, the hours from 6:00 a.m. to 9:00 a.m. and 3:00 p.m. to 6:00 p.m. are considered peak hours; all other hours are off-peak.

6 At the completion of the Hiawatha LRT line, Metro Transit - the lead transit agency in the Twin Cities region - undertook a significant restructuring of the bus system. Most changes in this restructuring were made to integrate the new light-rail line with the regional transit system. These changes include realigning routes to provide feeder/distributor services for LRT and discontinuing sections of routes that would duplicate LRT service. Areas with re-routed and discontinued services have shown slight declines in accessibility. 


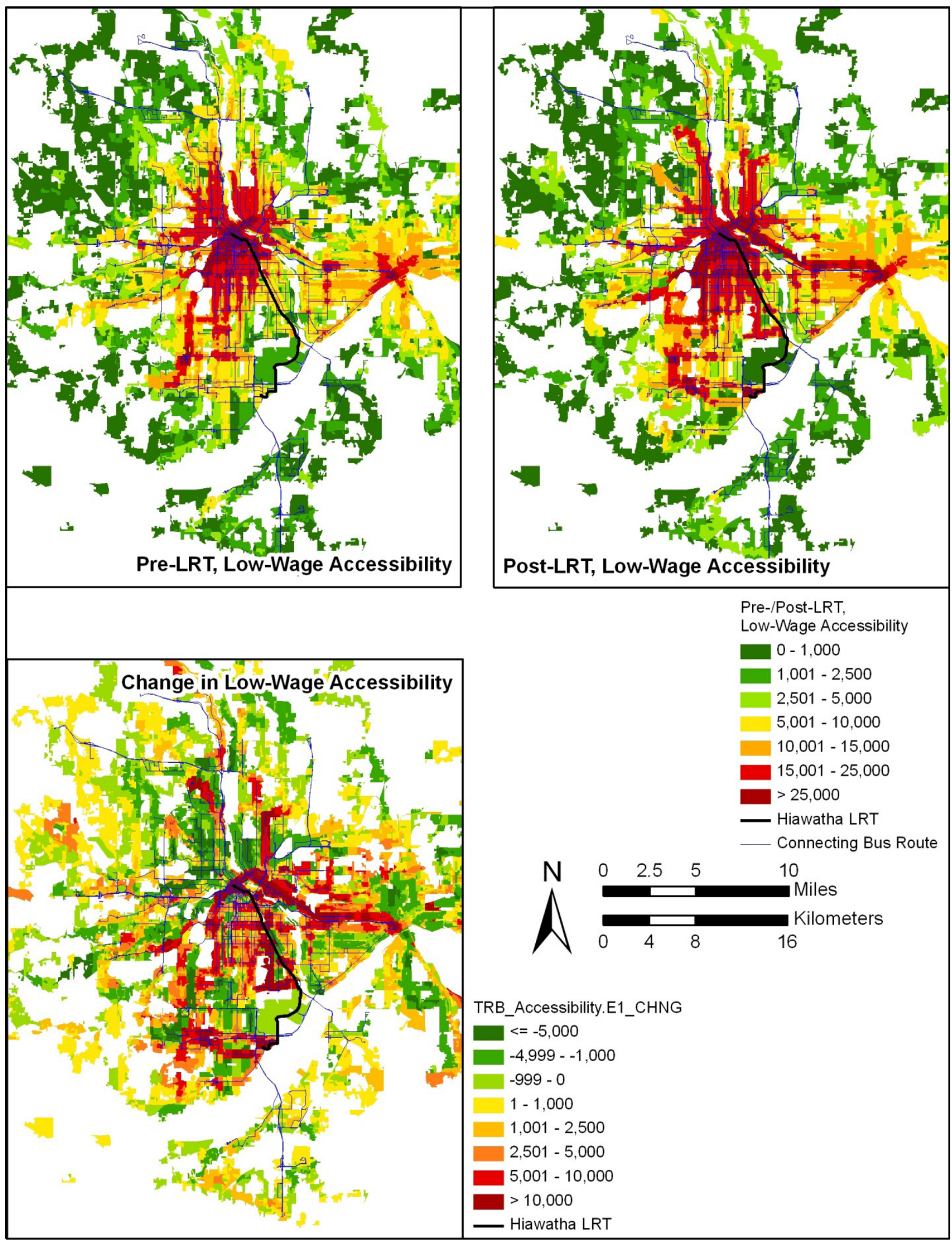

Figure 3: Transit accessibility to low-wage jobs, comparing 2002 and 2006. 
section in Table 1 shows descriptive statistics for job accessibility change measures, i.e., measures describing changes in census-block-level 30-minute cumulative accessibility by transit (with a maximum of one route transfer) to low-, medium-, or high-wage jobs before and after the opening of the Hiawatha LRT line.

As shown in Table 1 , mean values of accessibility change variables are all positive, indicating that on average job accessibility in the region increased in all wage categories after the implementation of LRT and concurrent reconfiguration of the bus network. The amount of increase is not even across the three wage categories: on average 1216 additional low-wage jobs become reachable within 30 minutes of transit travel after the implementation of the Hiawatha LRT, as do an additional 833 medium-wage jobs and 5075 high-wage jobs. The different amounts of increase are partly due to the three wage categories having different starting points and the low-, medium-, and high-wage categories not being thirds of the metropolitan job market-high-wage jobs greatly outnumber low- and medium-wage jobs. Standard deviations for the accessibility variables are greater than means, showing considerable variation in transit-based employment accessibility based upon census block centroids within the transit service area.

To confirm the key finding in Figure 3 that the Hiawatha LRT's impact extends well beyond station areas and into areas with bus-LRT connections, we divide blocks served by transit into three categories: blocks served by the LRT line, blocks served by bus routes that offer LRT connections within 30 minutes, and blocks served only by regular bus routes. Figure 4 shows percent change in accessibility before and after the LRT implementation by the three types of transit service areas. All the area types experience accessibility gains in LRT station areas and along connecting bus routes. The low- and high-wage categories experience gains along regular bus routes as well, but the medium-wage category shows a small loss in accessibility along regular bus routes. For all three wage groups, LRT station areas experience the greatest relative gains by far, followed by areas served by connecting bus routes. This finding confirms the importance of bus-LRT connections in broadening accessibility gains after the opening of the Hiawatha LRT line. When compared by wage categories, high-wage jobs experience larger percentage gains than low- and medium-wage jobs.

Table 1: Descriptive statistics.

\begin{tabular}{|c|c|c|c|c|}
\hline $\mathrm{N}=22588$ blocks & Mean & Std. Dev. & Min & Max \\
\hline \multicolumn{5}{|l|}{ Dependent variable: Job accessibility change variables } \\
\hline Change in low-wage job accessibility & 1216 & 4735 & -16712 & 29703 \\
\hline Change in medium-wage job accessibility & 833 & 7402 & -31783 & 47327 \\
\hline Change in high-wage job accessibility & 5075 & 13880 & -51635 & 93694 \\
\hline \multicolumn{5}{|l|}{ LRT-related variables } \\
\hline Downtown LRT & 0.004 & 0.060 & 0 & 1 \\
\hline South LRT & 0.003 & 0.056 & 0 & 1 \\
\hline Suburb LRT & 0.001 & 0.023 & 0 & 1 \\
\hline Connection LRT & 0.393 & 0.488 & 0 & 1 \\
\hline \multicolumn{5}{|l|}{ Control variables } \\
\hline Pre-LRT low-wage job accessibility & 7610 & 8285 & 0 & 64622 \\
\hline African American (\%) & 5.595 & 12.943 & 0 & 100 \\
\hline Latino (\%) & 3.332 & 8.037 & 0 & 100 \\
\hline Asian (\%) & 4.137 & 9.534 & 0 & 100 \\
\hline Single-parent family (\%) & 17.859 & 13.589 & 0 & 100 \\
\hline College degree (\%) & 33.404 & 19.058 & 0 & 93 \\
\hline Owner-occupied (\%) & 63.852 & 40.741 & 0 & 100 \\
\hline Zero-vehicle household (\%) & 10.744 & 12.344 & 0 & 87.7 \\
\hline Median household income $(\$ \mathrm{~K})$ & 51.579 & 21.975 & 0 & 200 \\
\hline
\end{tabular}




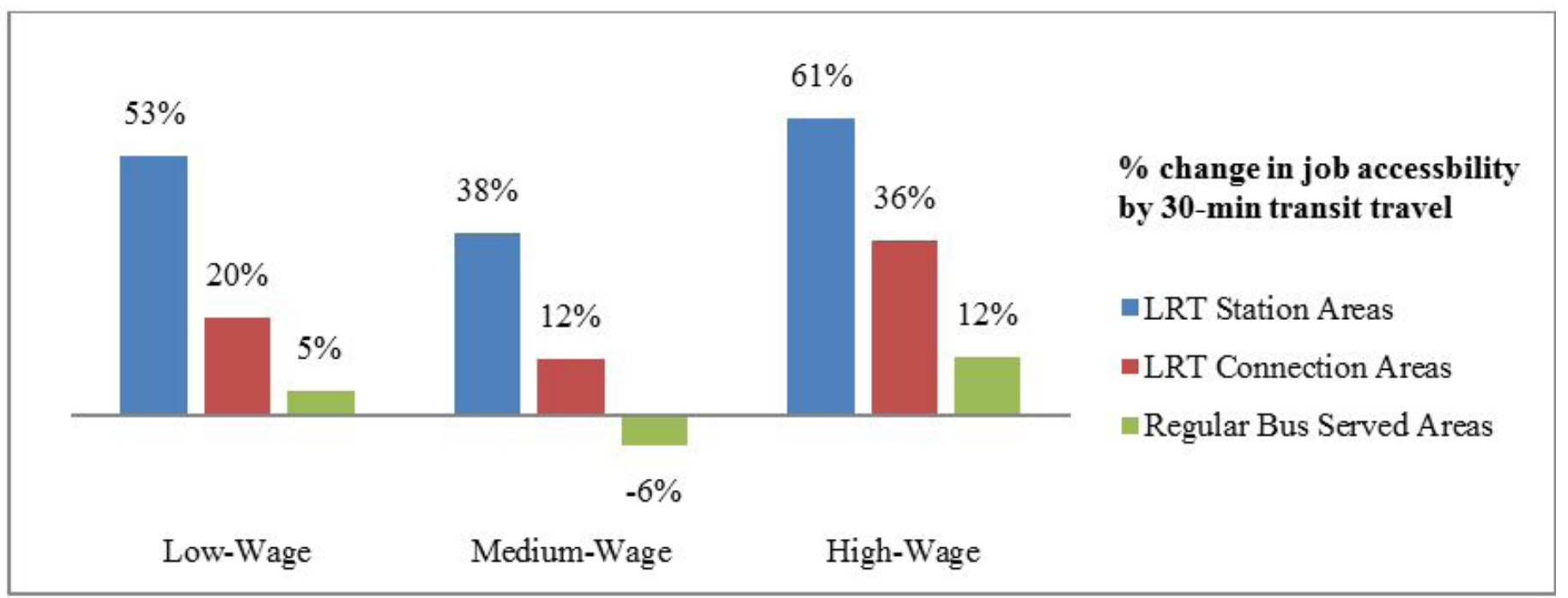

Figure 4: Percent changes in low-, medium-, and high-wage job accessibility by service type.

However, such a comparison does not control for other factors that might contribute to the changes at these locations. In the next section, we present a regression analysis that will help to estimate changes in accessibility at different locations after controlling for other explanatory factors.

\subsection{Regression analysis}

We estimate three separate ordinary-least-squares regression models to describe how the Hiawatha LRT implementation relates to changes in low-, medium-, and high-wage job accessibility measures. The detailed model specifications are as follows:

$\Delta A_{\text {low }}, \Delta A_{\text {medium }}, \Delta A_{\text {high }},=\beta_{0}+\beta_{L R T} * X_{L R T}+\beta_{\text {control }} * X_{\text {control }}+\epsilon$ where $\Delta A_{\text {low }}$ is the post-LRT accessibility change of low-wage jobs, $\Delta A_{\text {medium }}$ is the post-LRT accessibility change of mediumwage jobs, and $\Delta A_{\text {high }}$ is the post-LRT accessibility change of high-wage jobs. $X_{L R T}$ is a set of key explanatory variables that indicate LRT-relevant locations. This set of variables will help to test the hypothesis that accessibility increases in the region are significantly related to the implementation of LRT. $X_{\text {control }}$ is a set of control variables described below. Descriptive statistics of the key explanatory variables and control variables are presented in Table 1.

Variables describing LRT-relevant locations in this regression analysis include:

Downtown LRT: Dummy variable identifying blocks to which the nearest transit stop is an LRT station in downtown Minneapolis. Positive coefficients expected.

North LRT: Dummy variable identifying blocks to which the nearest transit stop is the Cedar-Riverside, Franklin Avenue, or Lake Street-Midtown LRT station. Positive coefficients expected.

South LRT: Dummy variable identifying blocks to which the nearest transit stop is the 38th Street, 46th Street, 50th Street-Minnehaha Park, or VA Medical Center LRT station. Positive coefficients expected.

Suburb LRT: Dummy variable identifying blocks to which the nearest transit stop is an LRT station in suburban Bloomington. Positive coefficients expected.

Connection LRT': Dummy variable identifying blocks to which the nearest transit stop is a bus stop offering a direct connection to LRT so that a rider could travel from that stop to a light-rail stop, wait five minutes (i.e., half the average LRT headway) for a train, and travel at least one stop by LRT within 30 minutes. Positive coefficients expected.

As shown above, this research breaks LRT station areas into four groups: downtown LRT, north LRT, south LRT, and suburb LRT. The classification is based on differences in urban forms and built environments (i.e., downtown versus suburb) and differences in socioeconomic characteristics across station areas. There is a significant divide between the Cedar-Riverside, Franklin Avenue, and Lake Street-Midtown station areas (the north LRT category) and the $38^{\text {th }}$ Street, $46^{\text {th }}$ Street, $50^{\text {th }}$ Street-Minnehaha Park, and VA Medical Center station areas (the south LRT category). The north LRT station areas are surrounded by dense, urban neighborhoods including significant amounts of public housing and low-income residents. The south LRT station areas, although still in Minneapolis, take on a more suburban feel and are dominated by single-family

7 Based on the times Twin Cities transit providers charge peak and offpeak fares, the hours from 6:00 a.m. to 9:00 a.m. and 3:00 p.m. to 6:00 p.m. are considered peak hours; all other hours are off-peak. 
housing and more middle-class residents. Distinguishing these station areas will help us provide a rich interpretation of the analysis findings.

The control variables in this regression analysis include:

- Pre-LRT job accessibility: Number of low-, medium-, and high-wage jobs reachable within 30-minute transit travel from the block centroid in 2002 before the implementation of the Hiawatha LRT. Negative coefficients are expected. This is because the Hiawatha LRT is not an intra-urban corridor but a corridor linking urban areas with suburban areas_-as such, areas with relatively low baseline accessibility are likely to see greater accessibility gains.

- Distance to nearest transit stop: Distance in hundreds of feet from each block centroid to the nearest transit stop, regardless of the type of transit stops. We expect larger accessibility gains in blocks closer to transit stops.

- Hi-Frequency bus: Dummy variable identifying blocks to which the nearest transit stop is a bus stop served by a Hi-Frequency bus route with no LRT connection. Positive coefficients expected. (Regular bus service is omitted as the reference category.)

This regression analysis also includes a set of demographic variables as control variables. This is because most service practices at Metro Transit are oriented towards areas with significant concentrations of socioeconomically disadvantaged populations, renters, and zero-vehicle households. The demographic variables in this analysis include percentages of African American residents, Latino residents, Asian residents, single-parent

Table 2: Regression results.

\begin{tabular}{|c|c|c|c|}
\hline \multicolumn{4}{|c|}{ Dependent variable $=$ Before-after change in number of jobs by type within 30 minutes by transit } \\
\hline & Model 1 & Model 2 & Model 3 \\
\hline & $\underline{\text { Low-wage jobs }}$ & $\underline{\text { Medium-wage jobs }}$ & High-wage jobs \\
\hline \multicolumn{4}{|l|}{ Key explanatory variable } \\
\hline Downtown LRT & $14,259.031^{* * *}$ & $18,904.961^{* * *}$ & $19,663.491^{* * *}$ \\
\hline North LRT & $8,282.851^{* * *}$ & $13,626.505^{* * *}$ & $22,698.052^{* * *}$ \\
\hline South LRT & $11,652.523^{* * *}$ & $18,347.581^{* * *}$ & $37,933.302^{* * *}$ \\
\hline Suburb LRT & $6,977.594^{* * *}$ & $11,405.500^{* * *}$ & $33,664.773^{* * *}$ \\
\hline Connection LRT & $1,814.218^{* * *}$ & $3,294.392^{* * *}$ & $7,683.292^{* * *}$ \\
\hline \multicolumn{4}{|l|}{ Control variables } \\
\hline Pre-LRT low-wage job accessibility & $-0.121^{* * *}$ & & \\
\hline Pre-LRT medium-wage job accessibility & & $-0.208^{* * *}$ & \\
\hline Pre-LRT high-wage job accessibility & & & $-0.110^{* * *}$ \\
\hline Dist. to nearest transit stop (100’) & $-63.937^{* * *}$ & $-119.541^{* * *}$ & $-274.169^{* * *}$ \\
\hline Hi-frequency bus & $2,506.573^{* * *}$ & $4,137.235^{* * *}$ & $6,957.125^{* * *}$ \\
\hline African American (\%) & $-24.503^{* * *}$ & $-36.409^{* * *}$ & $-26.345^{* * *}$ \\
\hline Latino $(\%)$ & $15.812^{* * *}$ & $25.416^{* * *}$ & $73.204^{* * *}$ \\
\hline Asian (\%) & $8.501^{* * *}$ & -2.728 & -2.644 \\
\hline Single-parent family (\%) & $-25.448^{* * *}$ & $-35.211^{* * *}$ & $-28.377^{* * *}$ \\
\hline College degree (\%) & $57.257^{* * *}$ & $102.038^{* * *}$ & $138.706^{* * *}$ \\
\hline Owner-occupied (\%) & $-5.959^{* * *}$ & $-11.665^{* * *}$ & $-17.696^{* * *}$ \\
\hline Zero-vehicle household (\%) & $17.630^{* * *}$ & $28.155^{* * *}$ & $62.096^{* * *}$ \\
\hline Median household income $(\$ K)$ & $-49.230^{* * *}$ & $-80.328^{* * *}$ & $-112.557^{* * *}$ \\
\hline Constant & $2,653.180^{* * *}$ & $3,928.345^{* * *}$ & $6,328.680^{* * *}$ \\
\hline \multicolumn{4}{|l|}{ Summary statistics } \\
\hline Number of blocks & 22,588 & 22,588 & 22,588 \\
\hline R-square & 0.196 & 0.191 & 0.233 \\
\hline F-test ( $p$ value) & & & \\
\hline
\end{tabular}


families, college graduates, owner-occupied housing units, and zero-vehicle households in the census block. Median household income of the block is also included as a control variable.

Table 2 shows the results of the three regression models. F-tests show all three models are statistically significant. Model 3 has a higher goodness of fit than models 1 and 2, implying that changes in high-wage job accessibility are easier to explain with the available variables than low- and medium-wage job accessibility. Across the models, the LRT-relevant locational variables produce significant and positive coefficients, implying the significant contribution of the LRT implementation to low-, medium-, and high-wage job accessibility in the region. The downtown and south LRT dummies produce particularly large coefficients, corresponding to gains of roughly 14,000 and 12,000 additional jobs per block. To summarize, LRTassociated accessibility benefits for low-wage workers are highest in the downtown and south LRT station areas, followed by north and suburban station areas. Bus-LRT connection areas produce a coefficient nearly as high as Hi-Frequency bus routes. This is significant because most LRT connections are provided by basic local routes with much lower service levels than the Hi-Frequency routes offer.

Most coefficients in Table 2 cannot be compared across models or, within a model, across variables. This is because the coefficients correspond to absolute gains in job accessibility, which is not comparable across locations or wage categories. Different locations have different starting points (i.e., different pre-LRT job accessibility), and the low-, medium-, and highwage categories have different shares of the metropolitan job market. To make coefficients comparable for key explanatory variables, we calculate percentage changes in job accessibility at LRT-related locations by standardizing the estimated absolute accessibility gain in each wage category at each location by the location's average baseline job accessibility in the wage category. Table 3 presents the calculated percentage changes.

As shown in Table 3, downtown and north LRT station areas have respectively seen 30 percent and 40 percent increases in low-wage job accessibility. The magnitude of these increases is larger than the increases in medium- and high-wage job accessibility in the areas. In south, suburban, and connection LRT areas, the magnitude of increases in low-wage job accessibility is similar to increases in medium-wage job accessibility but smaller than increases in high-wage job accessibility. This indicates that while low-wage workers in downtown and north LRT station areas benefited relatively to a greater degree from the LRT implementation than medium- and high-wage workers in those areas, low-wage workers in other LRT-related areas benefited less than their high-wage counterparts.

It is worth noting that although the connection LRT dummy variable produces significantly lower coefficients than the LRT station dummies do, it represents consistent accessibility gains impacting a much larger area and consequently many more workers. As shown in Figure 2, the bus-LRT connection routes reach much larger areas than the 12-mile long LRT line. The behavior of the connection LRT dummy is an indication of the broader, regional impact of the Hiawatha LRT on job accessibility. More importantly, its impact underscores the importance of good bus-LRT connections in broadening the impact scope of LRT lines. In other words, we may not attribute the positive and significant accessibility increase observed in the connection areas to the Hiawatha LRT itself, but the good integration of the Hiawatha LRT with the existing transit system in the Twin Cities region.

Note that the assumed maximums of one transfer and a quarter-mile walking distance used in the accessibility calculations in this research likely understate the actual importance of light-rail connections for routes that connect outside downtown. Since suburban employment centers are considerably larger than the walking distance assumption, many commutes to these areas would either require more than a quarter-mile $(400 \mathrm{~m})$ walk or an additional short bus ride at the destination end. Accessibility gains associated with trips with more than quarter-mile walking distances and multiple bus transfers are not captured by this analysis.

In terms of control variables, pre-LRT job accessibility is associated with negative accessibility changes across the

Table 3: Calculated percentage changes in job accessibility at LRT-related locations.

\begin{tabular}{cccc}
\hline Location Types & Low-Wage Jobs & Medium-Wage Jobs & High-Wage Jobs \\
\hline Downtown LRT & $30.17 \%$ & $23.40 \%$ & $18.14 \%$ \\
North LRT & $39.56 \%$ & $36.46 \%$ & $39.30 \%$ \\
South LRT & $188.96 \%$ & $174.22 \%$ & $240.00 \%$ \\
Suburb LRT & $83.69 \%$ & $89.14 \%$ & $221.71 \%$ \\
Connection LRT & $13.66 \%$ & $15.07 \%$ & $24.62 \%$ \\
\hline
\end{tabular}

Note: The percentage changes in this table are the relative percentage changes of the listed location types above with nonLRT-related locations as the reference category. 
models. As expected, blocks that are farther from transit stops show smaller accessibility increases, and blocks that are served by high-frequency bus services show greater accessibility improvements. Blocks with higher percentages of Latino, Asian, college-graduate, and zero-vehicle residents show greater accessibility improvements. Blocks with higher percentages of African American residents and owner-occupied housing units show smaller accessibility increases. Blocks with higher median household incomes also have smaller accessibility increases. Together, these results indicate a complex relationship between the benefits of transit improvements and social characteristics in areas served. Accessibility benefits associated with the Hiawatha LRT implementation appear to be oriented towards areas with high concentrations of low-income population, Latinos, and Asians, as well as areas with more college graduates, renters, and zero-vehicle households.

\section{Conclusions and discussion}

Our analysis of before-after job accessibility changes shows that the Hiawatha light-rail line has generated significant job accessibility benefits for all workers, including low-, medium-, and high-wage workers. In areas near downtown and north LRT stations, the magnitude of accessibility increases among lowwage workers is larger than that of medium- and high-wage workers who live in the areas. Yet, in other LRT station areas as well as in areas served with bus routes connecting LRT, lowwage workers benefited less than their high-wage counterparts. As such, a careful consideration of both what the Hiawatha line does well for low-wage workers and what it could possibly do better may inform both the planning of future transit corridors and ongoing planning for areas and connecting transit services surrounding Hiawatha stations. A summary of key findings of this study and discussion of their policy implications follows:

A spatial mismatch exists in the Twin Cities. As shown in Figure 2, major concentrations of low-wage workers and lowwage jobs often do not match up. While significant concentrations of low-wage workers are primarily located in Minneapolis and St. Paul (the two central cities in the region), clusters of low-wage jobs tend to be scattered throughout the metropolitan area. The spatial mismatch phenomenon-combined with relatively high rates of transit dependency among low-wage workers - underscores the importance of transit service as a provider of economic opportunities for low-wage workers.

The Hiawatha light-rail line, being well connected with the rest of the transit system in the Twin Cities, has significantly improved accessibility to all jobs, including low-, medium-, and high-wage jobs. Both the map analysis and regression analysis conducted in this study show significant, positive changes in employment accessibility by transit after the introduction of light-rail transit. Such a finding holds special significance for low-wage workers, as they are much more likely than others to be transit dependent. In planning future transit development in the Twin Cities region, it will be important to keep in mind that high-quality transit service (both bus and rail) can be a powerful tool for improving the lives of the poor.

Good bus-LRT connections are essential in broadening the impact scope of LRT implementations. One of the most interesting findings of the study is the large areas of accessibility gains found along bus routes that connect with light rail. They suggest the enormous importance of a fully integrated transit network (as opposed to a single transit corridor) in realizing maximum benefits from major transit investments. The effective and efficient planning of feeder/distributor services will be critical to ensuring low-wage workers reap the greatest benefits possible from future LRT corridors.

\section{References}

American Public Transportation Association. 2009. Ridership report archive. http://www.apta.com/resources/statistics/ Pages/RidershipArchives.aspx.

Bania, N., L. Leete, and C. Coulton. 2008. Job access, employment and earnings: Outcomes for welfare leavers in a US urban labour market. Urban Studies, 45(11): 2179-2202. doi:10.1177/0042098008095864.

Blumenberg, E. and M. Manville. 2004. Beyond the spatial mismatch: Welfare recipients and transportation policy. Journal of Planning Literature, 19(2): 182-205. doi:10.1177/0885412204269103.

Blumenberg, E., P. Ong, and A. Mondschein. 2002. Uneven access to opportunities, welfare recipients, jobs and employment support services in Los Angeles. UCTC Paper No 545, University of California Transportation Center. http://www.uctc.net/papers/545.pdf.

Cervero, R., O. Sandoval, and J. Landis. 2002. Transportation as a stimulus of welfare-to-work: Private versus public mobility. Journal of Planning Education and Research, 22(1): 50-63. doi: 10.1177/0739456X0202200105.

DeFina, R. H. 2007. A comparison of poverty trends and policy impacts for working families using different poverty indexes. Working Papers 07-13, Federal Reserve Bank of Philadelphia. http://ideas.repec.org/p/fip/fedpwp/07- 13.html.

Gardner, J. M. and D. E. Herz. 1992. Working and poor in 1990. Monthly Labor Review, 115(12): 20-28. http://stats. bls.gov/opub/mlr/1992/12/art2full.pdf.

Giuliano, G. 2005. Low income, public transit, and mobility. Transportation Research Record: Journal of the Transportation 
Research Board, 1927:63-70. doi: 10.3141/1927-08.

Glaeser, E. L., M. E. Kahn, and J. Rappaport. 2008. Why do the poor live in cities?: $5 \mathrm{e}$ role of public transportation. Journal of Urban Economics, 63(1): 1-24. doi:10.1016/j. jue.2006.12.004.

Joassart-Marcelli, P. 2005. Working poverty in southern California: Towards an operational measure. Social Science Research, 34(1): 20-43. doi:10.1016/j.ssresearch.2003.11.004.

Kain, J. 1992. 5e spatial mismatch hypothesis: 5ree decades later. Housing Policy Debates, 3(2): 371-460. http://www. stanford.edu/group/scspi/_media/pdf/Reference\%20Media/Kain_1992_Transportation.pdf.

Kain, J. F. 1968. Housing segregation, Negro employment, and metropolitan decentralization. The Quarterly Journal of Economics, 82(2): 175-197. doi: 10.2307/1885893.

Kawabata, M. 2002-07-01. Job access and work among autoless adults in welfare in Los Angeles. Working Paper 40, $5 \mathrm{e}$ Ralph and Goldy Lewis Center for Regional Policy Studies. http://www.escholarship.org/uc/item/6bq3457v.

Kawabata, M. 2003. Job access and employment among lowskilled autoless workers in US metropolitan areas. Environment and Planning A, 35(9): 1651-1668. doi:10.1068/ a35209.

Klein, B. W. and P. L. Rones. 1989. A profile of the working poor. Monthly Labor Review, 112(10): 3-13. http://www. bls.gov/mlr/1989/10/art1full.pdf.

Metropolitan Council of the Twin Cities. 2006. Metropolitan council transit rider survey.

Niece, J. 2003. No seat, no fare. Alternatives Journal, 29(1): 29.ISSN 12057398.

Ong , P. and D. Houston. 2002. Transit, employment andwomen on welfare. Urban Geography, 23(4): 344-364. doi:10.2747/0272-3638.23.4.344.

Pickrell, D. H. 1992. Adesire named streetcar: Fantasy and fact in rail transit planning. Journal of the American Planning Association, 58(2): 158-176. doi:10.1080/01944369208975791.

Rast, J. 2004. Transportation equity and access to jobs in metropolitan Milwaukee. 5e University of Wisconsin-Milwaukee Center for Economic Development. http://www4. uwm.edu/ced/publications/transp804.pdf.

Rosenbloom, S. 1992. Reverse commute transportation: Emerging provider roles. Drachman Institute, Tucson, AZ. http://ntl.bts.gov/data/num/808a.pdf.

Rosenbloom, S. and G. J. Fielding. 1998. Transit markets of the future: the challenge of change. TCRP 28, Federal Transit Administration. http://onlinepubs.trb.org/onlinepubs/tcrp/tcrp_rpt_28-a.pdf.

Sanchez, T. W. 1999. 5e connection between public transit and employment. Journal of the American Planning Association,
65(3): 284-296. doi: 10.1080/01944369908976058.

Sanchez, T. W. 2008. Poverty, policy, and public transportation. Transportation Research Part A: Policy and Practice, 42(5): 833-841. doi: 10.1016/j.tra.2008.01.011.

Sanchez, T. W., Q. Shen, and Z. Peng. 2004. Transit mobility, jobs access and low-income labour participation in U.S. metropolitan areas. Urban Studies, 41(7): 1313-1331. doi: 10.1080/0042098042000214815. 